\title{
A comparative study on eating behaviour among early and late adolescent girls
}

\author{
ANUBHA VIKAL AND MEENU AGARAWAL
}

Received: 23.09.2016; Revised: 05.10.2016; Accepted: 20.10.2016

DABSTRACT : The present study was done to compare the eating behaviour among early (11$16 \mathrm{yrs}$ ) and late (17-22 yrs) adolescent girls of district Ghaziabad. To evaluate the effect of age and socio-economic status on eating behaviour among the population of district Ghaziabad, total 500 subjects, were selected by stratified multistage random sampling technique from Modinagar and Ghaziabad. Majority of respondents were educated, unmarried, belonged to nuclear family and from middle income group (LIG). The data reflect the choice of food and the effect of nutrients on eating habits of these two age groups with different economic conditions.

KEY WORDS: Eating behaviour, Stratified multistage random sampling, Adolescent

- HOW TO CITE THIS PAPER : Vikal, Anubha and Agarawal, Meenu (2016). A comparative study on eating behaviour among early and late adolescent girls. Asian J. Home Sci., 11 (2) : 346-349, DOI: 10.15740/ HAS/AJHS/11.2/346-349. 